\title{
STRATEGIC LIQUIDITY SUPPLY AND SECURITY DESIGN*
}

\author{
by \\ Bruno Biais \\ Université de Toulouse (GREMAQ-IDEI-CRG), and CEPR \\ and \\ Thomas Mariotti \\ London School of Economics and Political Science
}

Contents:

Abstract

1. Introduction

2. The Basic Model

3. Liquidity Supply

4. Security Design

5. Robustness

6. Conclusion

Appendix

References

Discussion Paper

No.TE/03/445

January 2003
The Suntory Centre

Suntory and Toyota International Centres for Economics and Related Disciplines London School of Economics and Political Science Houghton Street London WC2A $2 \mathrm{AE}$ Tel.: 020-7955 6698

\footnotetext{
"We would like to thank Mike Fishman, Martin Hellwig, Roman Inderst, Bruno Jullien, Nobu Kiyotaki, Jean-Jacques Laffont, David Martimort, Benny Moldovanu, John Moore, Patrick Rey, Jean-Charles Rochet, Ernst Ludwig von Thaden, and Jean Tirole, as well as seminar participants at Mannheim University, the London School of Economics and Political Science, Northwestern University, Lausanne University and Toulouse University, for insightful comments.
} 


\begin{abstract}
We study how securities and trading mechanisms can be designed to optimally mitigate the adverse impact of market imperfections on liquidity. Asset owners seek to obtain liquidity by selling their claims on future cash-flows, on which they have private information. Our analysis encompasses both the cases of competitive and monopolistic liquidity supply. In the optimal trading mechanism associated to an arbitrary given security, issuers with low cash-flows sell their entire holdings of the security, while issuers with larger cash-flows are typically excluded from trade. By designing the security optimally, issuers can eshew exclusion altogether. The optimal security is debt. Because of its low informational sensitivity, debt mitigates the adverse selection problem. Furthermore, by pooling all issuers with high cashflows, debt also reduces the ability of a monopolistic liquidity supplier to exclude them from trade in order to better extract rents from issuers with low cash-flows.
\end{abstract}

Keywords: Security design, liquidity, mechanism design, adverse selection, financial markets imperfections.

JEL Nos.: G32, L14.

(C) by the authors. All rights reserved. Short sections of text, not to exceed two paragraphs, may be quoted without explicit permission, provided that full credit, including (c) notice, is given to the source.

Contact address: Dr Thomas Mariotti, Department of Economics, London School of Economics and Political Science, Houghton Street, London, WC2A 2AE, UK. Email: t.mariotti@Ise.ac.uk 


\section{INTRODUCTION}

While corporate finance offers insights in the design of optimal securities (see, e.g., Townsend (1979), Gale and Hellwig (1985), Allen and Gale (1988), Harris and Raviv (1989)), market microstructure analyzes how different trading mechanisms can offer variable degrees of liquidity, emphasizing the consequences of adverse selection and strategic behavior. We borrow from these two approaches to study the interaction between security design and market mechanisms. Our objective is to study how the design of securities and markets can mitigate imperfections and thus enhance the liquidity and efficiency of the issuance and trading processes.

To motivate our analysis, consider an entrepreneur who owns a project yielding random cash-flows in the future. Because of impatience or liquidity needs, she would like to sell today claims on these cash-flows. Brealey and Myers (2000, Chapter 15, page 419) describe the issuance process as follows:

"Suppose that your company is likely to need up to $\$ 200$ million of new long term debt over the next year or so. It can file a shelf registration for that amount. It then has prior approval [from the SEC] to issue up to $\$ 200$ million of debt, but it isn't obligated to issue a penny. [...] Now you can sit back and issue debt as needed, in bits and pieces if you like. Suppose Merrill Lynch comes across an insurance company with $\$ 10$ million ready to invest in corporate bonds. Your phone rings. It's Merrill Lynch offering to buy $\$ 10$ million of your bonds, priced to yield, say, $81 / 2$ percent. If you think that's a good price, you say 'OK' and the deal is done [...] Here is another possible deal. Suppose that you see a window of opportunity in which interest rates are temporarily low. You invite bids for $\$ 100$ million of bonds. Some bids may come from large investment banks acting alone; others may come from ad hoc syndicates. But that's not your problem; if the price is right, you just take the best deal offered."

This description underscores the process by which a security is designed and then marketed. It points at the role of the buyers in posting price offers, which the issuer can accept or not. The security can be purchased and priced by a single financial institution, Merrill Lynch in the example, or it can be offered to several possible buyers, and sold to the highest bidder. Our model reflects these stylized facts, and, in particular, encompasses the case where the financial institution has market power.

As a matter of fact, the underwriting industry is highly concentrated. Brealey and Myers (2000, Chapter 15, page 415) report that the six largest underwriters (Merrill Lynch, Salomon Smith Barney, Morgan Stanley, Goldman Sachs, Lehman Brothers, and JP Morgan) manage the majority of the securities issues. Along with the major role of large banks, Benveniste, Busaba and Wilhelm (2002) point at the niche occupied by 
specialized financial institutions. For example, they report that, out of fifteen truckingindustry IPOs completed between 1990 and 1994, nine were managed by one bank (Alex. Brown). They further argue that issues are often priced by a single financial intermediary. Empirically, the market power of financial intermediaries and market makers has been evidenced in several contexts (see Christie and Schultz (1994), or Chen and Ritter (2000)). Theoretically, it has been traced back to institutional constraints and private information. Thus the banking literature emphasizes that market power may arise because of capital adequacy requirements that limit entry, or because banks with preexisting relationships with firms are in a privileged position to lend to them (see Freixas and Rochet (1997)).

In addition to market power, a second imperfection is likely to hamper the efficiency of the security issuance process: firms issuing securities are often likely to have private information about their future cash-flows. As shown by Leland and Pyle (1977) and Myers and Majluf (1984), this creates an adverse selection problem, reducing the liquidity of the market and the gains from trade that could be reaped by the issuers. The goal of the present paper is to analyse the security design and issuance process in presence of market power and adverse selection. In particular, we endeavor to shed light on the following issues:

(i) Through what channels does market power affect liquidity? How does it exacerbate the lemons problem induced by adverse selection?

(ii) How do issuers react to the market power of financial intermediaries? How can they mitigate the illiquidity it induces? Does this alter qualitatively the type of security they issue?

Our analysis is in line with the insightful recent paper by DeMarzo and Duffie (1999). In both papers, while the security is designed under homogeneous information, it is then traded after the issuer has observed a private signal on the profitability of her assets. The preferences and information sets in our paper are similar to theirs. There are two major differences with their approach. First, we analyse the consequences of the market power of financial intermediaries. In contrast, they study competitive liquidity suppliers earning zero expected profits in a signaling game similar to Kyle's (1985). Second, we take a mechanism design approach to analyze the trading process. Thus, in our analysis both the design of the security and the design of the issuance mechanism are endogenous.

More precisely, in our model, liquidity suppliers offer trading mechanisms, to which the issuer reacts. In this screening game, the liquidity suppliers place transfer schedules, specifying the prices at which they are willing to buy variable quantities. The issuer then selects from this menu of offers the trade size maximizing her expected utility. To highlight the consequences of market power we analyse two extreme cases, namely the 
case of a single monopolistic liquidity supplier, and the case of competitive liquidity suppliers. The set of trading mechanisms we analyze encompasses the simple case where the financial intermediaries post a single price, as in the above quote from Brealey and Myers. It is also consistent with the IPO process where investors place offers to buy a variable number of shares at certain prices, either through indications of interest in the book building process or through bids in IPO auctions. ${ }^{1}$

For a given security design, the outcome of the trading interaction between the issuer and the liquidity suppliers has the following characteristics. The worse the private signal of the issuer, the more she is eager to sell the security, and the greater her trade. As in Akerlof (1970), the "good types", i.e., the issuers with large future cash-flows, are those who suffer the most from the adverse selection problem. Because of the linearity of the problem, there is a "bang-bang" solution, reflecting partial market break-down. Issuers with cash-flows above a certain threshold are entirely excluded from trade. In contrast, issuers with cash-flows below this threshold sell $100 \%$ of their holdings of the security. It follows that the optimal trading mechanism can be implemented in a very simple way. Each financial intermediary offers to buy the security by posting a linear price schedule. The issuer is then free to accept any of these offers. Note that this exactly fits Brealey and Myers' description of the issuance process as quoted above.

Reflecting the adverse selection problem, and the nature of the screening game we analyse, the endogenous cost function of the liquidity suppliers takes the form of lowertail conditional expectations, as in Glosten (1994) and Biais, Martimort and Rochet (2000). This implies that, as long as a non-empty set of issuers are excluded from the market, the price at which the liquidity suppliers are willing to purchase any amount of the security is strictly lower than the unconditional expectation of the value of the security. This is analogous to the small trade spread arising in screening models of market microstructure. While the qualitative features of the market outcome are the same in the monopolistic and competitive cases, the spread, and correspondingly the fraction of issuer types excluded from trade, are greater with a monopolistic liquidity supplier. Very much in line with the classical IO paradigm, the monopolist prefers to reduce the volume of trade by excluding more types, in order to extract greater rents from the types who remain in the market.

Our results contrast with DeMarzo and Duffie (1999), where (i) infinitesimal trades have an infinitesimal impact on prices, (ii) issuers sell a fraction of the security (which is interpreted as collateralization or tranching), and (iii) the good types are not entirely excluded from the market. The difference in results is due to the difference in trading mechanisms. Note that the separating equilibrium allocation obtained by DeMarzo and

\footnotetext{
${ }^{1}$ Hanley and Wilhelm (1995) or Cornelli and Goldreich (1998) document empirically the placement of orders in the book building process. Biais and Faugeron-Crouzet (2002) discuss IPO auctions. Benveniste, Wilhelm and Yu (1999) present empirical evidence on the determination of quantities sold by issuing firms after bids have been placed.
} 
Duffie (1999) is implementable in our mechanism. In the competitive case, however, the ex-ante efficiency of the allocation we characterize is greater than that of any equilibrium of their trading game. More generally, the competitive screening model we analyze allows to characterize the upper bound on the gains of trade that can be achieved given the agents' preferences and information.

While, as discussed above, adverse selection and market power induce inefficiencies, the issuer designs the security to mitigate these imperfections and increase the gains from trade. In line with the stylized fact that debt is the major source of outside financing (see, e.g., Grindblatt and Titman (1998, page 5)), we find that the optimal security is a debt contract. This result reflects two phenomena. First, as in Myers and Majluf (1984) and DeMarzo and Duffie (1999), debt mitigates the adverse selection problem, by making the payoff of the security less sensitive to the high cash-flow realizations. Second, and this is a distinctive contribution of our analysis, debt mitigates the adverse consequences of market power on the gains from trade. To maximize profits, the monopolistic liquidity supplier seeks to reduce the rents earned by the agents with low cash flows, by making it costly for them to mimick the good types. When the payoff of the security increases smoothly with the cash-flow from the project (as with equity), this is achieved by excluding the best types from trade. This partial market break-down is avoided with debt, as long as the face value is not too high. Indeed, with debt contracts, the payoff of the security is the same for all issuers with future cash-flows above the debt service. Hence the liquidity supplier must either include them all, or exclude them all from the market. Since the latter would be quite costly, as it would imply loosing a large fraction of the most profitable customers, he prefers to design his schedule so that all issuers participate to the market. Hence, the optimal design of the security enables to entirely avoid exclusion from the market. In contrast with the signaling model of DeMarzo and Duffie (1999), all issuers types sell $100 \%$ of their security holdings. Correspondingly, there is no informational content of trades: the expectation of the value of the security given a sale is equal to its unconditional value. This low information content of the sale of debt securities in our model is in line with the results of several empirical studies (see, e.g., Dann and Mikkelson (1984), Eckbo (1986), and Mikkelson and Partch (1986)).

One could argue that there are three limitations to our analysis. First, we assume that the issuer initially designs one security, and is then restricted to that security. ${ }^{2}$ Second, for technical reasons, we require that both the security payoff and the residual claim of the agent be increasing in the final cash-flow generated by the asset. This rules out mechanisms which have been shown to be optimal in other security design analyses, such as the "live-or-die" contract obtained by Innes (1990) in a moral hazard context.

\footnotetext{
${ }^{2}$ This is in line with DeMarzo and Duffie (1999), but differs from Nachman and Noe (1994), where the security is designed by the agent after she has observed her private information, and thus conveys a signal of the profitability of her assets.
} 
Third, while we analyse the competitive case as an information-constrained Pareto optimum, one might wonder if it could emerge from an actual trading game, where liquidity suppliers would post competing schedules. We show that our analysis is robust to these three limitations. First, we analyze, in the competitive case, the situation where, instead of one security, the issuer initially designs a menu of securities, among which she will be able to choose at the trading stage. We find that the equilibrium allocations arising in this more general setting are exactly the same as those arising in our basic model. Furthermore, no monotonicity assumption is needed to obtain the optimality of debt. We also study the case where several liquidity suppliers post non-exclusive competing transfer schedules. We show that the trades arising in the competitive case are a Nash equilibrium of this oligopolistic liquidity supply game.

The paper is organized as follows. The model is described in Section 2. In Section 3 , we analyse the design of the trading mechanism. In Section 4, we turn to the security design problem. Extensions of our analysis are presented in Section 5. Section 6 concludes.

\section{The BAsic Model}

Our model is in line with DeMarzo and Duffie's (1999). We extend their paper along two dimensions. First, we consider arbitrary trading mechanisms. Second, we allow for market power on the part of the liquidity supplier.

\subsection{The Extensive-Form of the Game}

Agents. There are two agents, an issuer and a liquidity supplier. The issuer owns assets that generate future cash-flows $X$ drawn from an absolutely continuous c.d.f. $G$ with positive density $g$ over a compact interval $\mathcal{X}=[\underline{x}, \bar{x}] \subset \mathbb{R}_{++}$. Both agents are risk-neutral and the market interest rate is normalized to zero. The issuer has an incentive to raise cash by selling part of her assets. The reason for this is that she is more impatient than the liquidity supplier. We accordingly denote by $\delta \in(0,1)$ the issuer's discount factor, while the liquidity supplier's is normalized to one. The ex-ante private value of the assets to the issuer is thus lower than the value they have for the liquidity supplier. There are therefore gains from trade from transferring the assets from the issuer to the liquidity supplier.

Security Design. In order to raise cash, the issuer designs a limited-liability security backed by her assets. In general, the payoff of this security may depend on any ex-post contractible information. For simplicity, we assume that the payoff $F$ of this security can only be made contingent on the realized cash-flow $X$, i.e., there exists a measurable mapping $\varphi: \mathcal{X} \rightarrow \mathbb{R}_{+}$such that $F=\varphi(X)$. As Harris and Raviv (1989) or Nachman and Noe (1994), we shall in a first step restrict the set of admissible securities by imposing the following limited liability and monotonicity conditions: 
(LL) $\varphi(x) \in[0, x]$ for all $x \in \mathcal{X}$;

(M) $\varphi$ is non-decreasing on $\mathcal{X}$;

$(\mathrm{MR}) \operatorname{Id}_{\mathcal{X}}-\varphi$ is non-decreasing on $\mathcal{X}$,

where $\operatorname{Id}_{\mathcal{X}}$ is the identity function on $\mathcal{X}$. Conditions $(\mathrm{M})-(\mathrm{MR})$ require that both the payments to the liquidity supplier and to the issuer be non-decreasing in the realized cash-flow. Together with (LL), they imply that the set $\Phi$ of admissible securities payments is a subset of Lipschitz functions on $\mathcal{X}$. We denote by $\mathcal{F}=[\underline{f}, \bar{f}]$ the interval of feasible payments associated to an admissible security $F$.

Timing and Information Structure. There are two periods, and five stages. The sequence of events in the first period is as follows:

(i) First, the agent designs the security $F$;

(ii) Next, a trading mechanism $T:[0,1] \rightarrow \mathbb{R}$ is designed for the sale of any fraction $q \in[0,1]$ of the securitized asset;

(iii) The issuer privately learns the realization of the cash-flows $X$;

(iv) If the issuer accepts the trading mechanism $T$, she trades a volume $q$ of the security, for which she obtains a transfer $T(q)$.

Finally, in the second period,

(v) The value $X$ of the cash-flows is publicly revealed and any remaining consumption takes place.

We shall return in more detail to the question of who designs the trading mechanism at stage (ii). Meanwhile, two features of this extensive form are worth emphasizing. First, the issuer has perfect advance knowledge of the cash-flows at the interim stage (iii). This differs from DeMarzo and Duffie (1999), who allow for noisy private signals. Second, the issuer designs her security before she learns the realization of the cashflows. Therefore, unlike in Nachman and Noe (1994), the choice of a security cannot be used by the issuer as a signal of the profitability of her assets. The assumption that, at stage (i), the issuer designs a single security, rather than a menu of securities, will be relaxed in Section 5 .

This extensive form of the game is in line with the description of the issuance process offered by Brealey and Myers (2000) and quoted in our introduction. Anticipating that it will need funds in the future, the firm designs the security and goes through the shelfregistration process. This corresponds to stage (i) in our game. Once the security is shelf-registered, it can be issued some time later, for example one year later. This corresponds to stage (iv) in our game. 
Our model is also consistent with the case where the security is first designed and sold to an intermediary at stage (i), and then resold by the intermediary at stage (iv). Consider for instance a manufacturing firm that will generate cash-flows in the future, and currently needs cash. It initially sells to a financier a security with payoff contingent on these cash-flows (this corresponds to stage (i) in our game). The financier can be a bank providing a loan, a supplier providing trade credit, or a venture capitalist purchasing convertible bonds. After this initial exchange, the financier naturally receives information about the project (this corresponds to stage (iii) in our game). The financier may be itself subject to a liquidity shock, and thus led to demand liquidity from the market. ${ }^{3}$ To obtain liquidity, it sells the security it holds in its portfolio (this corresponds to stage (iv) in our game). The price at which it initially purchases the security from the manufacturing firm reflects its rational expectations about future market liquidity. The security is initially designed to maximize market liquidity, and correspondingly the initial sale price.

\subsection{Comparison with DeMarzo and Duffie (1999)}

The first main difference between our model and the setting considered by DeMarzo and Duffie (1999) is that we take an alternative approach to modeling the trading game. They consider a signaling game, whereby the issuer, after observing her signal, chooses the size of her trade, and the liquidity suppliers react to this quantity by quoting prices. In contrast, we take a mechanism design approach. The trading mechanism is a menu of pairs $\{q, T(q)\}_{q \in[0,1]}$, from which the informed agent selects her optimal trade. This menu of trades, designed before the private signal is observed, can be interpreted as a screening mechanism. If the transfer schedule $T$ is concave, it amounts to a sequence of limit orders, as in Biais, Martimort and Rochet (2000). The allocation arising in the separating equilibrium considered by DeMarzo and Duffie (1999) is implementable in the trading mechanism. It is not the optimal allocation, however, as established in the next section. This is because the screening mechanism yields more commitment power, as the liquidity supplier can commit to a menu of trades before the quantity $q$ is observed. ${ }^{4}$

The second difference is that, while in the context of the signaling model, competitive liquidity supply is warranted, we allow for strategic liquidity supply. We consider

\footnotetext{
${ }^{3}$ In the case of a bank, the need for liquidity can be due to prudential rules (see Dewatripont and Tirole (1994)). In the case of a trade creditor it can stem from a transient cash-flow gap, or an investment opportunity, combined with credit rationing constraints. In the case of a venture capitalist it can reflect an opportunity to invest in new projects combined with constraints on raising new funds.

${ }^{4}$ This commitment power makes it possible to engineer cross-subsidization between the issuer's types. Indeed, in the equilibrium of our screening model, the liquidity supplier will earn profits when trading with issuers whose cash-flows are high, while he will make losses when trading with issuers whose cash-flows are low. This cross-subsidization of the bad types by the good types also takes place in the screening games analyzed by Glosten (1994) and Biais, Martimort and Rochet (2000).
} 
two polar cases. In the monopolistic case, the trading mechanism is designed at stage (ii) by the liquidity supplier, to maximize his expected profit, under the incentive and participation constraints of the informed agent. The latter constraint requires that the informed agent accepts to participate in the trading mechanism at stage (iv). In the alternative case, referred to as the competitive case, the trading mechanism is designed at stage (ii) by the issuer to maximize her expected utility, subject to the participation constraint of the liquidity suppliers. By comparing the allocations arising in the monopolistic case and in the competitive case, we shed some light on the consequences of market power for market liquidity.

\subsection{Incentive Compatibility Conditions}

Given a security design $F$, and a transfer schedule $T$, the issuer selects what fraction $q$ of the security to sell to the liquidity supplier, conditional on her private information about future cash-flows. At this interim stage, since the issuer has perfect advance knowledge of the cash-flows, and since the security's payoff is only contingent on these, she also perfectly knows the realization $f=\varphi(x)$ of $F$. Her utility is $T(q)+\delta(x-f q)$, while the profit of the liquidity supplier is $q f-T(q)$. Thus, the type of the issuer is entirely summarized by $f$, and the set of possible types is $\mathcal{F}$.

The Lemons Problem. An issuer with type $f \in \mathcal{F}$ finds it attractive to trade $q$ rather than not to trade at all and consume $\delta x$ if and only if:

$$
f \leq \frac{T(q)}{\delta q}
$$

This condition holds if the security payoff $f$ is low enough, the unit price $\frac{T(q)}{q}$ of the security is high enough, and $\delta$ is low enough so that the issuer is sufficiently impatient. Overall, the willingness to trade reveals a relatively low type. This underscores the nature of the adverse selection problem arising in our model, which is very much in line with Akerlof's (1970) lemons problem.

Implementable Mechanisms. Under adverse selection, the trading mechanism must be incentive compatible and satisfy the issuer's individual rationality constraint for all realizations of $f$. There is no loss of generality in applying the revelation principle (Myerson (1979)). I.e., any implementable allocation achieved via a transfer schedule $T$ can also be achieved via a truthful direct mechanism $(\tau, q): \mathcal{F} \rightarrow \mathbb{R} \times[0,1]$ that stipulates a transfer and a trading volume as a function of the issuer's report of her type $f \in \mathcal{F}$. Incentive compatibility requires that:

$$
f \in \underset{\hat{f} \in \mathcal{F}}{\arg \max } \tau(\hat{f})-\delta f q(\hat{f}) ; \quad f \in \mathcal{F} .
$$


We denote by $U_{F}$ the corresponding informational rent:

$$
U_{F}(f)=\sup _{\hat{f} \in \mathcal{F}} \tau(\hat{f})-\delta f q(\hat{f}) .
$$

$U_{F}$ is analogous to the informational rent of a regulated firm with privately observed marginal cost $\delta f$, as in Baron and Myerson (1982). We take the dual approach and characterize the set of pairs $\left(U_{F}, q\right)$ that correspond to an incentive compatible mechanism. This set is characterized in the following lemma.

Lemma 1 A pair $\left(U_{F}, q\right)$ is implementable if and only if:

(i) $U_{F}$ is convex on $\mathcal{F}$;

(ii) For almost every $f \in \mathcal{F}, \dot{U}_{F}(f)=-\delta q(f)$.

Lemma 1 simply reflects the fact that $U_{F}$ is the upper enveloppe of a family of affine and decreasing functions of $f$. Convexity of $U_{F}$ together with $\dot{U}_{F}=-\delta q$ implies the following important property.

Lemma 2 In any implementable allocation, the volume of trade $q$ is non-increasing in the security payoff $f$, and consequently in the cash-flow $x$.

The intuition is in the line of Akerlof (1970). As discussed above, issuers with relatively large future cash-flows are relatively less eager to trade at a given price than issuers with lower future cash-flows. That issuers with low cash-flows are always ready to trade depresses the price, which makes issuers with high cash-flows even less eager to trade. In the limit this can lead to a market break-down, where the issuers with the largest cash-flows obtain zero gains from trade. Lemmas 1 and 2, and their intuition are similar to Proposition 1 in DeMarzo and Duffie (1999).

Ex-Post Rationality Constraints. In addition to the above incentive compatibility constraint, a feasible trade mechanism must also satisfy the issuer's ex-post participation constraint. Specifically, since the issuer has always the option not to trade, and since in this case she cannot be compelled to pay anything to the liquidity supplier, the issuer's informational rent $U_{F}$ must always be non-negative:

$$
U_{F}(f) \geq 0 ; \quad f \in \mathcal{F} .
$$

Since $U_{F}$ is non-increasing by Lemma 1 , this simplifies to:

$$
U_{F}(\bar{f}) \geq 0 .
$$




\subsection{The Expected Utilities of the Agents}

Given a security $F$ and a schedule $T$, the expected profit of the liquidity supplier is:

$$
\int_{\mathcal{F}}\left(f q(f)-T(q(f)) d G^{\varphi}(f)\right.
$$

where $G^{\varphi}$ is the c.d.f. of the random variable $F=\varphi(X)$. Similarly, the ex-ante expected informational rent of the issuer is :

$$
\int_{\mathcal{F}}(T(q(f))-\delta f q(f)) d G^{\varphi}(f)
$$

Adding the expected profits of the liquidity supplier and the expected rent of the issuer, we obtain the total gains from trade:

$$
(1-\delta) \int_{\mathcal{F}} f q(f) d G^{\varphi}(f) .
$$

Thus, the gains from trade are an increasing function of the difference between the discount rate of the liquidity suppliers and that of the issuer, and of the amount of cash-flows transferred from the second period to the first.

\subsection{Ex-Ante Efficiency}

As a benchmark, we first consider the case where a benevolent social planner chooses a trading mechanism so as to maximize social welfare. Following Holmström and Myerson (1983), efficiency is defined at an ex-ante stage, i.e., before the issuer learns the value of the future cash-flows. Thus an ex-ante optimal mechanism solves:

$$
\sup _{(T, q)} \int_{\mathcal{F}}(T(q(f))-\delta f q(f)) d G^{\varphi}(f)
$$

subject to the liquidity supplier's participation constraint:

$$
\int_{\mathcal{F}}\left(f q(f)-T(q(f)) d G^{\varphi}(f) \geq \underline{\pi}\right.
$$

for some $\underline{\pi} \geq 0$. Solving this program is immediate. The participation constraint of the liquidity supplier is binding, and the optimal trading volume is $q=1$. It follows then from (7) that an equity contract maximizes the expected gains from trade.

\section{LIQUIDITY SUPPLY}

In this section, we analyze the optimal price-quantity schedule for a given security design $F$. We consider the two polar cases of competitive and monopolistic liquidity supply. In the competitive case, the schedule $T$ is designed by the issuer, who extends a take-it-or-leave it offer to the liquidity supplier; the situation is reversed in the monopolistic case. 
The Competitive Case. We first consider the case where the issuer has all the bargaining power. Given a security $F$, the issuer's problem is to design the transfer schedule $T$ to maximize her expected rent (6), subject to her incentive compatibility condition (1), her ex-post individual rationality condition (3), and the participation constraint of the liquidity supplier, that his expected profit be non-negative. Recall that the expected rent of the issuer is equal to the expected total gains from trade minus the expected profit of the liquidity supplier:

$$
\int_{\mathcal{F}}(1-\delta) f q(f) d G^{\varphi}(f)-\int_{\mathcal{F}}(f q(f)-T(q(f))) d G^{\varphi}(f) .
$$

To maximize her rent, the issuer designs the schedule so as to saturate the participation constraint of the liquidity supplier and set his expected profit to zero. The liquidity supplier's zero-profit condition simplifies the program of the issuer to the choice of a trading volume $q$ which maximizes the overall expected gains from trade (7) under her incentive compatibility condition, characterized in Lemma 1, and her ex-post participation constraint (4). The only difference between this problem and the design of the ex-ante efficient allocation is the ex-post participation constraint, since the ex-ante efficient trading profile is incentive compatible.

The Monopolistic Case. Now turn to the case where the liquidity supplier has all the bargaining power. The liquidity supplier's task is to choose a transfer schedule $T$ in order to maximize his expected profit (5), subject to the incentive compatibility condition (1) and the ex-post individual rationality condition (3). Recall that the expected profit of the liquidity supplier is equal to the expected total gains from trade minus the expected informational rent of the issuer:

$$
\int_{\mathcal{F}}(1-\delta) f q(f) d G^{\varphi}(f)-\int_{\mathcal{F}}(T(q(f))-\delta f q(f)) d G^{\varphi}(f) .
$$

The relevant constraints are again the incentive compatibility conditions, characterized in Lemma 1, and the ex-post participation contraint (4). Since the informational rent is non-increasing, the participation constraint of the issuer must be binding at the upper end of the support $\mathcal{F}$.

The Optimal Trading Mechanism. The menus $\left(\tau^{c}, q^{c}\right)$ and $\left(\tau^{m}, q^{m}\right)$ offered respectively by the issuer and by the liquidity supplier are characterized in the following proposition.

Proposition 1 There exist $f_{F}^{c} \geq f_{F}^{m}$ and $\tau_{0}^{c} \geq \tau_{0}^{m}=0$ such that, for all $f \in \mathcal{F}$, and for $i \in\{c, m\}$,

(i) $\tau^{i}(f)=\tau_{0}^{i}+\delta f_{F}^{i}$ whenever $f \leq f_{F}^{i}$ and $\tau^{i}(f)=\tau_{0}^{i}$ otherwise;

(ii) $q^{i}(f)=1$ whenever $f \leq f_{F}^{i}$ and $q^{i}(f)=0$ otherwise. 
Moreover, $\tau_{0}^{c}=0$ whenever $f_{F}^{c}<\bar{f}$.

In both the competitive and the monopolistic cases, issuers with cash-flows below a the threshold $f_{F}^{i}$ sell $100 \%$ of the security, while issuers above this threshold do not trade at all. Correspondingly, issuers with small future cash-flows obtain large gains from trade, while issuers with large future cash-flows can face a market break-down, and obtain no gains from trade. This "bang-bang" solution differs markedly from the signaling equilibrium analyzed by DeMarzo and Duffie (1999), where the trade smoothly decreases with the issuer's type. As in the monopoly pricing model of Riley and Zeckhauser (1983), it arises because of the combined effect of the linearity of the preferences and the screening nature of the trading game.

In order to saturate the liquidity supplier's break-even constraint in the competitive case, it can be necessary to allow for a lump-sum transfer $\tau_{0}^{c}$ given to the issuer independently of her trade. This can however only arise when no type of the issuer is excluded from trade. Indeed, when some types are excluded from trade, it is preferable to increase the price of the security, in order to make trading more attractive for the good types and thus minimize the extent of the market break-down, rather than giving a lump-sum transfer.

As the threshold value of the cash-flow above which the issuer exits the market is greater in the competitive than in the monopolistic case, more gains from trade are achieved in the former than in the latter. This bears some analogy with credit rationing models such as Bolton and Scharfstein (1990), or market microstructure models such as Biais, Martimort and Rochet (2000). The intuition is that the monopolistic liquidity supplier trades off the benefits of a high volume of trade against the incentive costs of inducing the issuer to reveal truthfully low realizations of the cash-flows. This rentefficiency trade-off is less acute when the issuer designs the trading mechanism, since the rent extraction motive is not present.

Implementation. The optimal transfer schedule can be implemented with a limit order to buy, or bid price, posted by the liquidity supplier, at which he stands ready to buy up to one unit of the security. ${ }^{5}$ Saturating the participation constraint of the liquidity supplier and, for simplicity, neglecting the lump-sum tax $\tau_{0}^{i}$, we obtain the price at which the competitive liquidity supplier purchases the security:

$$
\frac{\int_{\underline{f}}^{f_{F}^{c}} f d G^{\varphi}(f)}{G^{\varphi}\left(f_{F}^{c}\right)}=E\left(F \mid F \leq f_{F}^{c}\right) .
$$

\footnotetext{
${ }^{5}$ In line with the analogy drawn in the market microstructure literature between limit orders and options (Copeland and Galai (1983)), we can also interpret this arrangement as the option, for the issuer, to sell her securities at a predetermined price.
} 
This is reminiscent of the result obtained by Glosten (1994) in a screening model with competitive market makers, where the bid is equal to the lower tail expectation of the final value of the security. In the competitive case, the threshold $f_{F}^{c}$ above which issuers opt out from trading, and the bid price are pinned down by combining this lower tail expectation and the ex-post rationality condition of the issuer:

$$
\delta f_{F}^{c}=E\left(F \mid F \leq f_{F}^{c}\right) .
$$

In line with basic price theory, the valuation of the marginal issuer for the security is equated with the security's price.

The difference between the bid price and the unconditional expectation of the value of the security is similar to the bid-ask spread. The greater the probability mass corresponding to low cash-flow realizations, the lower the bid price, the wider the spread, and, consequently, the greater the mass of high cash-flows issuers who are deterred from trading. This is similar to the result obtained in screening models of market microstructure (Glosten (1989, 1994), Biais, Martimort and Rochet (2000)) that the small trade spread maps into the set of investors' types who are excluded from trade.

\section{Security Design}

In both the competitive and the monopolistic environments, the issuer's problem is to choose a security $F$, or equivalently a function $\varphi \in \Phi$, in order to maximize her expected rent, anticipating the equilibrium price at which she will be able to sell the securities. For simplicity we assume hereafter that:

$$
\frac{d}{d x}\left(\frac{G(x)}{g(x)}\right) \geq \frac{1-\delta}{\delta} ; \quad x \in \mathcal{X} .
$$

This condition is slightly stronger than the standard assumption of log-concavity of the density $g$. It ensures that one may neglect the constraint that $U_{F}$ be convex when solving for the optimal transfer schedule. In other terms, it enables us to focus on the first-order conditions of the mechanism design problem, while warranting that the second-order conditions hold.

\subsection{Debt and Equity}

To build some intuition about the security design problem, we first compare liquidity supply with debt and with equity.

Equity. If the issuer designs a pure equity contract, i.e., $\varphi=\operatorname{Id}_{\mathcal{X}}$, the optimal schedules $\left(\tau_{E}^{c}, q_{E}^{c}\right)$ and $\left(\tau_{E}^{m}, q_{E}^{m}\right)$ are as stated in the next proposition.

Proposition 2 If the issuer designs an equity contract, then: 
(i) In the competitive case, $f_{E}^{c}=\min \left\{\bar{x}, f^{c}\right\}$ where $f^{c}$ is the largest $f$ such that:

$$
\delta f=\frac{\int_{\underline{x}}^{f} \phi g(\phi) d \phi}{G(f)} .
$$

(ii) In the monopolistic case, $f_{E}^{m}=\min \left\{\bar{x}, f^{m}\right\}$, where $f^{m}$ is the largest $f$ such that:

$$
\frac{1-\delta}{\delta} f-\frac{G(f)}{g(f)} \geq 0
$$

When $f_{E}^{c}$ or $f_{E}^{m}$ is equal to $\bar{x}$, all issuer types achieve gains from trade. Otherwise, issuers with high cash-flows are excluded from the market. To determine if issuers with type $f$ should be excluded from the market, the monopolistic liquidity supplier compares the gains from trade $(1-\delta) f g(f)$ that can be achieved with these agents, with the rent $\delta G(f)$ they must be left. This rent increases with the cumulative distribution of types up to $f$, since, as incentive compatible rents are decreasing with types, rents left to type $f$ must be left to all types below $f$.

Debt. If the issuer designs a debt contract with face value $d$, i.e., $\varphi=\min \left\{\operatorname{Id}_{\mathcal{X}}, d\right\}$, the optimal schedules $\left(\tau_{D}^{c}, q_{D}^{c}\right)$ and $\left(\tau_{D}^{m}, q_{D}^{m}\right)$ are as stated in the next proposition. ${ }^{6}$

Proposition 3 If the issuer designs a debt contract with face value $d$, then:

(i) In the competitive case, $f_{D}^{c}=d$ if $d \leq d^{c}$ and $f_{D}^{c}=f_{E}^{c}$ otherwise, where $d^{c}$ is the largest $d$ such that:

$$
\int_{\underline{x}}^{d} f g(f) d f+(1-G(d)) d=\delta d .
$$

(ii) In the monopolistic case, $f_{D}^{m}=d$ if $d \leq d^{m}$ and $f_{D}^{m}=f_{E}^{m}$ otherwise, where $d^{m}$ is the largest $d$ such that:

$$
\int_{\underline{x}}^{d} f g(f) d f+(1-G(d)) d-\delta d=\int_{\underline{x}}^{f_{E}^{m}}\left(f-\delta f_{E}^{m}\right) g(f) d f .
$$

\footnotetext{
${ }^{6}$ In DeMarzo and Duffie (1999), the interpretation of $\min \{\operatorname{Id} \mathcal{X}, d\}$ as a standard debt contract requires the assumption that the unsold fraction of the security is not held on the balance sheet of the issuer at the time of default. This does not arise in our model, since, when the issuer trades, the security is entirely transferred to the liquidity supplier.
} 
The intuition is the following. In the competitive case, $d^{c}$ is the largest face value such that the liquidity supplier's participation constraint and the issuer ex-post rationality condition are consistent. If the face value of the debt is too high, $d>d^{c}$, market equilibrium then requires that the highest types, with cash-flow between $f_{E}^{c}$ and $d$, be excluded from the market. This effectively converts the debt contract into an equity contract, since for all the issuers who participate to the market, $\varphi(x)=x$. On the other hand, if $d \leq d^{c}$ then the participation constraint of the liquidity supplier is consistent with the ex-post rationality condition of all issuer types. In that case, all issuers sell their security, and thus reap gains from trade.

Now turn to the monopolistic case. When the issuer designs a debt contract with face value $d$, the liquidity supplier has the option to shut-down the upper tail of the payoff distribution by setting the price at which the issuer can sell his security to $f_{D}^{m}<\delta d$. If $d$ is larger than $d^{m}$, the highest face value of debt such that the liquidity supplier obtains the same expected profit than under an equity contract, it is indeed optimal for the monopolistic liquidity supplier to do so. The shut-down threshold is then optimally set at $f_{E}^{m}$. Just as the issuer in the competitive case, the liquidity supplier is effectively converting a debt contract into an equity one. On the other hand, if $d \leq d^{m}$, then all issuer types find it preferable to sell their security.

Debt Versus Equity. Since by assumption the support $\mathcal{X}$ of the cash-flow distribution is bounded, equity is just a particular case of debt with a face value equal to $\bar{x}$. Hence the optimal debt contract always weakly dominates a pure equity contract from the issuer's viewpoint. It is nevertheless interesting to determine exactly in which circumstances debt strictly dominates equity.

The same argument applies for both the competitive and monopolistic cases, $i \in$ $\{c, m\}$. We defined $d^{i}$ as the maximum face value such that a debt contract with face value $d \in\left[f_{E}^{i}, d^{i}\right]$ can always be entirely traded between the two agents. Note that a debt contract with $d=f_{E}^{i}$ is equivalent, from the issuer's point of view, to a pure equity contract. With the former, all issuers entirely sell the security, but the rent of issuers with cash-flows above $d$ is 0 . With the latter, only issuers with cash-flows up to $f_{E}^{i}$ sell the security. Moreover, $d^{i}>f_{E}^{i}$ whenever $f_{E}^{i}<\bar{x}$. Since the ex-ante utility of the issuer is clearly increasing in $d$, we have the following result.

Proposition 4 For any $i \in\{c, m\}$, if $f_{E}^{i}<\bar{x}$, then the issuer is always strictly better off designing an optimal debt contract with face value $d^{i}$ than an equity contract.

Technically, designing a debt contract is equivalent for the issuer to creating an atom at $d$ in the distribution of types. Since the liquidity supplier is making gains on the high types, he will not restrict the volume of trades provided that $d$ is not high enough to jeopardize the issuer's incentives. The latter is thus able to get a better price $\delta d$ for her shares and thereby to increase her level of utility. 


\subsection{Debt as the Optimal Security}

To begin with, we establish some useful properties of an optimal design that hold independently of the considered environment. The optimality of debt then requires a separate argument in the competitive and the monopolistic case.

Preliminaries. First, note that risk-free cash-flows are not subject to adverse selection problems. Hence, in the line of Myers and Majluf (1984), it is always optimal to sell these, in order to maximize trade and thus the gains from trade. Consequently, it is optimal to design the security to yield at least the worst possible realization of the cash-flow. This yields the following lemma.

Lemma 3 If $F$ is an optimal security, then $\varphi(\underline{x})=\underline{x}$.

Our next proposition is key to our results. The argument generalizes the result obtained when comparing debt and equity. Let $i \in\{c, m\}$, and consider a security $F$ with payoff $\varphi$ such that issuers above a certain threshold $f_{F}^{i}$ do not trade. What this proposition asserts is that the issuer could strictly gain by offering instead an alternative security, with payoff capped at a level slightly above the shut-down level $f_{F}^{i}$. That alternative security $F_{\varepsilon}$ would have payoff $\varphi_{\varepsilon}=\min \left\{\varphi, f_{F}^{i}+\varepsilon\right\}$, and would be such that all issuers would trade. Rationally anticipating the participation of all issuer types, including the better ones, the liquidity supplier would be ready to pay a slightly better price, $\delta\left(f_{F}^{i}+\varepsilon\right)$, than for $F$, as long as $\varepsilon$ is not high enough to make the issuer's incentives prohibitively expensive. At that price, issuers with high cash-flows would be willing to sell the security, given that its payoff is capped just above $f_{F}^{i}$. The increase in price implies that the security $F_{\varepsilon}$ strictly dominates the original security $F$ from the issuer's point of view. Given our assumptions on $F$, this implies that it is not optimal for the issuer to design a security involving shut-down for good types. Thus, we can state the following proposition.

Proposition 5 The optimality of security $F$ requires that all issuer types entirely sell their holdings to the liquidity supplier.

This result, which obtains in the context of the optimal trading mechanism characterized in the previous section, underscores its difference with the signaling models of Leland and Pyle (1977) and DeMarzo and Duffie (1999). In these models, an informed agent can credibly signal the quality of a project only by retaining part of the cashflows generated by this project. For an arbitrarily chosen security, the analogue of this phenomenon in our screening model is the possibility of market break-down. From the issuer's point of view, this way of signaling the quality of her assets is however very costly. Hence she is better off designing her security to avoid market break-down altogether. As a consequence, the market for an optimal security will be very liquid. For instance, in the competitive case, the price at which such a security will be traded will just be equal to the unconditional expectation $\int_{\mathcal{F}} f d G^{\varphi}(f)$ of the value of this security, thereby eliminating the bid-ask spread. 
The Competitive Case. The program of the issuer is to maximize the total gains from trade, subject to her own incentive compatibility and ex-post participation constraints at the trading stage, and to the zero-profit constraint of the liquidity suppliers. The analysis of Section 3 implies that these constraints simplify to a bang-bang trading structure, whereby issuers with types above a certain threshold do not trade, while those below entirely sell their security at a price equal to a lower tail expectation. Proposition 5 simplifies the situation further by mandating to concentrate only on securities such that there is no shut-down. Thus we can restate the issuer's problem of choosing an optimal security as an infinite-dimensional linear programming problem:

$$
\sup _{\varphi \in \Phi}(1-\delta) \int_{\mathcal{X}} \varphi(x) g(x) d x
$$

subject to the no shut-down condition:

$$
\int_{\mathcal{X}} \varphi(x) g(x) d x \geq \delta \varphi(\bar{x}) .
$$

This inequality can alternatively be seen as an ex-post participation constraint for the issuer, requiring that the price $\int_{\mathcal{X}} \varphi(x) g(x) d x$ of the security be greater than its present value for all issuer types, even for the issuer with the greatest possible cashflow, i.e., $\delta \varphi(\bar{x})$. Note that in formulating the issuer's problem, we have already taken into account the liquidity supplier's break-even constraint, which must be saturated at the optimum. The issuer's security design problem can then be analyzed as follows. Let us form the Lagrangian:

$$
L(\varphi, \lambda)=(1-\delta) \int_{\mathcal{X}} \varphi(x) g(x) d x+\lambda\left(\int_{\mathcal{X}} \varphi(x) g(x) d x-\delta \varphi(\bar{x})\right),
$$

where $\lambda$ is the Lagrange multiplier of the issuer's ex-post participation constraint. By (LL)-(M)-(MR), any $\varphi \in \Phi$ is absolutely continuous, the derivative $\dot{\varphi}$ is a.e. welldefined with $0 \leq \dot{\varphi} \leq 1$, and $\varphi(x)=\int_{\underline{x}}^{x} \dot{\varphi}(\xi) d \xi$ for all $x \in \mathcal{X}$. Hence, integrating by parts, we get:

$$
L(\varphi, \lambda)=-(1+\lambda-\delta) \int_{\mathcal{X}} \dot{\varphi}(x) G(x) d x+(1-\delta)(1+\lambda) \varphi(\bar{x}) .
$$

The maximization of $L(\varphi, \lambda)$ with respect to $\varphi$ can thus be treated as a standard optimal control problem. We then have the following result.

Proposition 6 Suppose that (8) holds. Then the debt contract with face value $d^{c}$ is an optimal security from the issuer's point of view. 
The intuition is that a debt contract trades-off in an optimal way two conflicting objectives. On the one hand, it is efficient to transfer as much cash-flows from the second period to the first. On the other hand, the lemons problem limits the extent to which this can be done. By imposing a cap on the security payoff, a debt contract minimizes this adverse selection cost, in support of Myers and Majluf's (1984) peckingorder hypothesis.

The Monopolistic Case. In the monopolistic case, the issuer designs the security to maximize her expected gain from trade, anticipating the optimal response of the monopolistic liquidity supplier, and her own reaction, reflected in her incentive compatibility and ex-post participation constraints. The issuer anticipates that the liquidity supplier will design his schedule to maximize his expected profit. She designs the optimal security to mitigate the adverse consequences of this rent extraction strategy on the gains from trade. From the previous section, we know that the transfer schedule optimally designed by the monopolistic liquidity supplier is a simple take-it-or-leaveit offer to buy all the security at a given price. In designing this offer the liquidity supplier trades-off the benefit from a large market, from which no issuer would be excluded, with the benefits of a smaller market, excluding issuers with high cash-flows, but extracting more rents from the others. Proposition 5 implies that with the optimal security there is no shut-down. Thus we can re-state the issuer's problem of choosing an optimal security as an infinite-dimensional linear programming problem:

$$
\sup _{\varphi \in \Phi} \delta \int_{\mathcal{X}}(\varphi(\bar{x})-\varphi(x)) g(x) d x
$$

subject to the no shut-down condition:

$$
\int_{\mathcal{X}}(\varphi(x)-\delta \varphi(\bar{x})) g(x) d x \geq \int_{\underline{x}}^{\tilde{x}}(\varphi(x)-\delta \varphi(\tilde{x})) g(x) d x ; \quad \tilde{x} \in \mathcal{X} .
$$

This can be interpreted by comparing the security design problem to a principal-agent problem with moral hazard. The principal is the issuer, who designs the security, while the agent is the liquidity supplier, and the moral-hazard variable is the decision by the agent to shut-down the market or not. The issuer's security design problem can then be analyzed as follows. Let us form the Lagrangian:

$$
\begin{aligned}
L(\varphi, \Lambda) & =\delta \int_{\mathcal{X}}(\varphi(\bar{x})-\varphi(x)) g(x) d x \\
& +\int_{\mathcal{X}}\left(\int_{\mathcal{X}}(\varphi(x)-\delta \varphi(\bar{x})) g(x) d x-\int_{\underline{x}}^{\tilde{x}}(\varphi(x)-\delta \varphi(\tilde{x})) g(x) d x\right) d \Lambda(\tilde{x}),
\end{aligned}
$$

where $\Lambda$ is the Lagrange multiplier associated to the no shut-down condition. It is a distribution function on $\mathcal{X}$, i.e., a non-decreasing, right-continuous function such that 
$\Lambda(\underline{x})=0$. The following lemma provides a sufficient condition for $\varphi \in \Phi$ to be an optimal security (see, e.g., Luenberger (1969, §8.4, Theorem 1)).

Lemma 4 Let $\varphi \in \Phi$, and $\Lambda$ be a distribution function on $\mathcal{X}$ such that:

$$
\int_{\mathcal{X}}\left(\int_{\mathcal{X}}(\varphi(x)-\delta \varphi(\bar{x})) g(x) d x-\int_{\underline{x}}^{\tilde{x}}(\varphi(x)-\delta \varphi(\tilde{x})) g(x) d x\right) d \Lambda(\tilde{x})=0
$$

and:

$$
L(\varphi, \Lambda) \geq L(\tilde{\varphi}, \Lambda) ; \quad \tilde{\varphi} \in \Phi .
$$

Then $\varphi$ is an optimal security in $\Phi$.

To prove the optimality of debt, we proceed as follows. Suppose that (8) holds. Then, by Proposition 3, the optimal debt contract from the issuer's viewpoint has face value $d^{m}$. Given this contract, the only point at which the liquidity supplier's shut-down constraint is binding is at the level $f_{E}^{m}$. This suggests taking as a Lagrange multiplier $\Lambda$ a point-mass at $f_{E}^{m}$, i.e., a mapping of the form $\Lambda_{\lambda}(x)=\lambda \chi_{\left\{x \geq f_{E}^{m}\right\}}$ for some $\lambda>0$. For this choice of $\Lambda$, the Lagrangian can be re-written as:

$$
\begin{aligned}
L\left(\varphi, \Lambda_{\lambda}\right) & =(1-\lambda) \delta \int_{\mathcal{X}}(\varphi(\bar{x})-\varphi(x)) g(x) d x \\
& +\lambda\left(\delta \int_{\underline{x}}^{f_{E}^{m}}\left(\varphi\left(f_{E}^{m}\right)-\varphi(x)\right) g(x) d x+(1-\delta) \int_{f_{E}^{m}}^{\bar{x}} \varphi(x) g(x) d x\right) .
\end{aligned}
$$

Proceeding as in the competitive case, this expression can be further simplified to:

$$
\begin{aligned}
L\left(\varphi, \Lambda_{\lambda}\right) & =(1-\lambda) \delta \int_{\mathcal{X}} \dot{\varphi}(x) G(x) d x \\
& +\lambda\left(\delta \int_{\underline{x}}^{f_{E}^{m}} \dot{\varphi}(x) G(x) d x+(1-\delta) \int_{f_{E}^{m}}^{\bar{x}} \varphi(x) g(x) d x\right) .
\end{aligned}
$$

It is clear from this expression that the second term on the right-hand side is maximized by setting $\varphi=\operatorname{Id}_{\mathcal{X}}$. The same is true for the first term if $\lambda \leq 1$. Overall, a pure equity contract maximizes the Lagrangian if $\lambda \leq 1$. But then, the no shut-down condition would not be binding, and Lemma 4 would not apply. This means that, in order to derive the optimality of debt, we must select $\lambda>1$. Intuitively, the shadow cost of the no shut-down condition must be high enough for debt to be an optimal security.

Lemma 5 There exists $\lambda>1$ such that $\varphi=\min \left\{\operatorname{Id}_{\mathcal{X}}, d^{m}\right\}$ maximizes $L\left(\varphi, \Lambda_{\lambda}\right)$ with respect to $\varphi \in \Phi$. 
Since for the debt contract $\varphi=\min \left\{\operatorname{Id}_{\mathcal{X}}, d^{m}\right\}$,

$$
\int_{\mathcal{X}}(\varphi(x)-\delta \varphi(\bar{x})) g(x) d x-\int_{\underline{x}}^{f_{E}^{m}}\left(\varphi(x)-\delta \varphi\left(f_{E}^{m}\right)\right) g(x) d x=0,
$$

the following result is an immediate consequence of Lemmas 4 and 5 .

Proposition 7 Suppose that (8) holds. Then the debt contract with face value $d^{m}$ is an optimal security from the issuer's point of view.

Just as in the competitive case, a debt contract is optimal from the issuer's point of view. The fact that the face value of debt is smaller than in the competitive case reflects the liquidity supplier's market power. It is interesting to note that, in both cases, the optimal security is risky debt. That this optimal security is informationally sensitive, stands in stark contrast with the results of DeMarzo and Duffie (1999). In their model, if the issuer observes a perfectly informative signal about the realization of the cash-flows, there exists an optimal security whose payoff does not depend on her private information and is identically equal to the lowest possible realization of the cash-flows, $\varphi=\underline{x}$. This difference between this result of and ours reflect both the difference between our screening trading mechanism and their signaling game, and, in the monopolistic case, the fact that the liquidity supplier would be able to extract all the rent if the security was not informationally sensitive.

\section{Robustness}

We now investigate the robustness of our results to some of the assumptions underlying our basic model.

\subsection{Menus of Securities}

So far, we have assumed that the choice of a security is made ex-ante. We now relax this assumption, by allowing the issuer to design ex-ante a menu of securities, from which she will select which to trade at the interim stage. ${ }^{7}$ A menu of securities is then a mapping $(x, \hat{x}) \mapsto \psi(x, \hat{x})$ such that $\psi(x, \hat{x}) \in[0, x]$ for all $(x, \hat{x}) \in \mathcal{X}^{2}$. For example, this includes the case where, if $\hat{x}$ is in a certain set, then the security is a debt contract, while if $\hat{x}$ is in the complementary set, then the security is an equity contract. Note that we do not impose any monotonicity condition on the menu of securities.

By the revelation principle, there is no loss of generality in focusing on truthful direct mechanisms $(\tau, q): \mathcal{X} \rightarrow \mathbb{R} \times[0,1]$ that stipulate a transfer and a trading

\footnotetext{
${ }^{7}$ Similar results would obtain if the menu of securities was designed instead by the financiers supplying liquidity to the issuer.
} 
volume as a function of the issuer's report of her type $x \in \mathcal{X}$. Incentive compatibility requires that:

$$
x \in \underset{\hat{x} \in \mathcal{X}}{\arg \max } \tau(\hat{x})-\delta \psi(x, \hat{x}) q(\hat{x}) ; \quad x \in \mathcal{X} .
$$

We now characterize the second-best efficient menu of securities $\psi$ and the associated trading structure $(\tau, q)$, that maximize the expected gains from trade. It is the solution to the following infinite-dimensional linear programming problem:

$$
\sup _{\tau, q, \psi}(1-\delta) \int_{\mathcal{X}} \psi(x, x) q(x) g(x) d x
$$

subject to the incentive compatibility condition (9), the individual rationality constraint of the issuer:

$$
\tau(x)-\delta \psi(x, x) q(x) \geq 0 ; \quad x \in \mathcal{X},
$$

and the break-even constraint of the liquidity supplier:

$$
\int_{\mathcal{X}} \psi(x, x) q(x) g(x) d x \geq \int_{\mathcal{X}} \tau(x) g(x) d x .
$$

There is no loss of generality in setting $\psi(x, \hat{x})=x$ for $\hat{x} \neq x$, as the only impact of such a change is to relax the issuer's incentive compatibility constraint. The intuition is that it is optimal to trade equity out of the equilibrium path, as this represents the maximal possible punishment that can be inflicted to the issuer. A similar reasoning implies that there is no loss in generality in setting $q(\hat{x})=1$ for all $\hat{x} \in \mathcal{X}$. Indeed, one can redefine the security $\psi$ so that $\tilde{\psi}(x, x)=\psi(x, x) q(x)$ and the incentive compatibility constraint is again relaxed by trading the maximal possible volume. It remains only to determine $\varphi(x)=\psi(x, x)$ for each $x \in \mathcal{X}$, as well as the optimal transfer $\tau$. Let $\bar{\tau}=\sup _{x \in \mathcal{X}} \tau(x)$. The functions $\varphi$ and $\tau$ solve:

$$
\sup _{\tau, \varphi}(1-\delta) \int_{\mathcal{X}} \varphi(x) g(x) d x
$$

subject to the incentive compatibility constraint:

$$
\tau(x)-\delta \varphi(x) \geq \bar{\tau}-\delta x ; \quad x \in \mathcal{X},
$$

the individual rationality constraint of the issuer:

$$
\tau(x)-\delta \varphi(x) \geq 0 ; \quad x \in \mathcal{X},
$$

and the break-even constraint of the liquidity supplier:

$$
\int_{\mathcal{X}} \varphi(x) g(x) d x \geq \int_{\mathcal{X}} \tau(x) g(x) d x .
$$


It is clear from (10)-(11) that for each $x \in \mathcal{X}$, one at least of these constraints must be binding. It is immediate to check that, for each $x \in \mathcal{X}$, the incentive compatibility constraint (10) is binding if and only if $x \leq \frac{\bar{\tau}}{\delta}$, and that the individual rationality constraint (11) is binding if and only if $x \geq \frac{\bar{\tau}}{\delta}$. Moreover the only value of $x \in \mathcal{X}$ where both constraints are binding is $\frac{\bar{\tau}}{\delta}$.

We now prove that the optimal $\varphi$ corresponds to the debt contract with face value $d^{c}$. The argument proceeds by showing that any pair $(\tau, \varphi)$ that solves the above problem is dominated by a debt contract with face value $\frac{\bar{\tau}}{\delta}$ and a constant transfer $\bar{\tau}$. The argument is twofold. Suppose first that $\varphi(x)<x$ for a set of values of $x \leq \frac{\bar{\tau}}{\delta}$ of positive measure, and consider an alternative design $\tilde{\varphi}$ that coincides with $\varphi$ for $x \geq \frac{\bar{\tau}}{\delta}$, and that satisfies $\tilde{\varphi}(x)=x$ for $x \leq \frac{\bar{\tau}}{\delta}$. Modify correspondingly $\tau$ for $x \leq \frac{\bar{\tau}}{\delta}$ by setting $\tilde{\tau}=\bar{\tau}$ on this interval of values of $x$. If feasible, this new design clearly dominates $\varphi$. It is immediate that constraints (10)-(11) are preserved. Consider now (12). Since it is satisfied under the initial contract,

$$
\begin{aligned}
\int_{\mathcal{X}} \varphi(x) g(x) d x & \geq \int_{\mathcal{X}} \tau(x) g(x) d x \\
& =\int_{\underline{x}}^{\frac{\bar{\tau}}{\delta}}(\bar{\tau}-\delta x+\delta \varphi(x)) g(x) d x+\int_{\frac{\bar{\tau}}{\delta}}^{\bar{x}} \tau(x) d x,
\end{aligned}
$$

where the equality follows from the fact that (10) is binding for $x \leq \frac{\bar{\tau}}{\delta}$. So, in particular, as $x \geq \varphi(x)$, we obtain that:

$$
\begin{aligned}
\int_{\mathcal{X}} \tilde{\varphi}(x) g(x) d x & =\int_{\underline{x}}^{\frac{\bar{\tau}}{\delta}} x g(x) d x+\int_{\frac{\bar{\tau}}{\delta}}^{\bar{x}} \varphi(x) g(x) d x \\
& \geq(1-\delta) \int_{\underline{x}}^{\frac{\bar{\tau}}{\delta}} \varphi(x) g(x) d x+\delta \int_{\underline{x}}^{\frac{\bar{\tau}}{\delta}} x g(x) d x+\int_{\frac{\bar{\tau}}{\delta}}^{\bar{x}} \varphi(x) g(x) d x \\
& \geq \bar{\tau} G\left(\frac{\bar{\tau}}{\delta}\right)+\int_{\frac{\bar{\tau}}{\delta}}^{\bar{x}} \tau(x) g(x) d x \\
& =\int_{\mathcal{X}} \tilde{\tau}(x) g(x) d x
\end{aligned}
$$

which implies that (12) holds under the new contract. Hence an optimal contract must have $\varphi(x)=x$ for all $x \leq \frac{\bar{\tau}}{\delta}$. Consider now the values of $x \geq \frac{\bar{\tau}}{\delta}$. We know that the individual rationality constraint (11) is binding for such $x$. Therefore one must have $\varphi(x) \leq \frac{\bar{\tau}}{\delta}$ by definition of $\bar{\tau}$. Suppose that $\varphi(x)<\frac{\bar{\tau}}{\delta}$ for a set of values of $x \geq \frac{\bar{\tau}}{\frac{\delta}{\tau}}$ of positive measure. Consider an alternative design that coincides with $\varphi$ for $x \leq \frac{\delta}{\delta}$ and that satisfies $\tilde{\varphi}(x)=\frac{\bar{\tau}}{\delta}$ otherwise. Modify correspondingly $\tau$ for $x \geq \frac{\bar{\tau}}{\delta}$ by setting 
$\tilde{\tau}=\bar{\tau}$ on this interval of values of $x$. If feasible, this new design clearly dominates $\varphi$. It is immediate that constraints (10)-(11) are preserved. Consider now (12). Since it is satisfied under the initial contract, and since $\tau(x)=\bar{\tau}$ for all $x \leq \frac{\bar{\tau}}{\delta}$,

$$
\begin{aligned}
\int_{\mathcal{X}} \varphi(x) g(x) d x & \geq \int_{\mathcal{X}} \tau(x) g(x) d x \\
& =\bar{\tau} G\left(\frac{\bar{\tau}}{\delta}\right)+\delta \int_{\frac{\bar{\tau}}{\delta}}^{\bar{x}} \varphi(x) g(x) d x
\end{aligned}
$$

where the equality follows from the fact that (11) is binding for $x \geq \frac{\bar{\tau}}{\delta}$. So, in particular, as $\frac{\bar{\tau}}{\delta} \geq \varphi(x)$ and $\varphi(x)=x$ for $x \leq \frac{\bar{\tau}}{\delta}$, we obtain that:

$$
\begin{aligned}
\int_{\mathcal{X}} \tilde{\varphi}(x) g(x) d x & =\int_{\underline{x}}^{\frac{\bar{\tau}}{\delta}} x g(x) d x+\left(1-G\left(\frac{\bar{\tau}}{\delta}\right)\right) \overline{\bar{\tau}} \\
& \geq \int_{\underline{x}}^{\frac{\bar{\tau}}{\delta}} x g(x) d x+(1-\delta) \int_{\frac{\bar{\tau}}{\delta}}^{\bar{x}} \varphi(x) g(x) d x+\left(1-G\left(\frac{\bar{\tau}}{\delta}\right)\right) \bar{\tau} \\
& \geq \bar{\tau} G\left(\frac{\bar{\tau}}{\delta}\right)+\left(1-G\left(\frac{\bar{\tau}}{\delta}\right)\right) \bar{\tau} \\
& =\bar{\tau}
\end{aligned}
$$

which implies that (12) holds under the new contract. Combining this with the earlier result, we obtain that $\varphi$ is a debt contract with face value $\frac{\bar{\tau}}{\delta}$. At an optimum, we must have $\frac{\bar{\tau}}{\delta}=d^{c}$ by Proposition 6 . Thus we can state the following proposition:

Proposition 8 If the issuer can design a menu of securities from which she selects which security to trade at the interim stage, and the liquidity supplier is competitive, the equilibrium allocations and the traded security are the same as in the basic model.

Furthermore, this shows that the monotonicity constraints (M)-(MR) are imposed without loss of generality in the basic model. In particular, "live-or-die" contracts in the spirit of Innes (1990) are never optimal.

\subsection{Oligopolistic Screening}

So far, we have focused on the case where the issuer designs the trading mechanism, or where there is a single liquidity supplier who acts as a monopolist. We now turn to the case where $I>1$ liquidity suppliers offer simultaneously non-exclusive pricequantity schedules $\left\{T_{i}\right\}_{i \in I}$ for the issuer's securities. Consistently with previous models of multiprincipal mechanism design (see, e.g., Stole (1990), Martimort (1992), or Biais, 
Martimort and Rochet (2000)), this can be seen as a situation of competition between trading mechanisms in which each principal cannot contract on the quantitities that are sold to his competitors. This corresponds to many situations observed in practice in financial markets where individual trades cannot be made contingent on the quotes or trades made by others.

The Trading Game. The timing is similar to that of the monopolistic trading game described in Section 2. Formally, steps (ii) and (iv) are replaced by:

(ii') The $I$ liquidity suppliers simultaneously post trading mechanisms $T_{i}:[0,1] \rightarrow \mathbb{R}$, $i \in I$, for the sale of any fraction $q_{i} \in[0,1]$ of the securitized asset;

(iv') If the issuer accepts the trading mechanisms $\left\{T_{j}\right\}_{j \in J}, J \subset I$, she trades volumes $\left\{q_{j}\right\}_{j \in J}$ of the security, $\sum_{j \in J} q_{j} \leq 1$, for which she obtains transfers $\left\{T_{j}\left(q_{j}\right)\right\}_{j \in J}$.

For a given security $F$, we focus on perfect Bayesian equilibria of this screening game. In these equilibria, liquidity suppliers post transfer schedules that are best response to the strategies of the other liquidity suppliers, given the behavior of the issuer in the subsequent stages of the game.

A Decentralization Result. Instead of characterizing the outcome of the non-exclusive trading game for an arbitrary security, we directly focus on the case where the issuer designs a security $F$ that involves no shut-down in the competitive case, and trade at a price $\delta \bar{f}{ }^{8}$ An example of this situation is whenever the issuer designs the debt contract that is optimal in the competitive case, i.e., $\varphi=\min \left\{\operatorname{Id}_{\mathcal{X}}, d^{c}\right\}$. No attempt is made to give a full characterization of the perfect Bayesian equilibria of the induced trading game. Rather, for this particular security, our aim is to construct an equilibrium that implements the same allocation and transfers than in the competitive case, i.e., $\sum_{i \in I} q_{i}=1$ and $\sum_{i \in I} T_{i}=\delta \bar{f}$. To do so, let us introduce the following candidate equilibrium strategies:

$$
T_{i}\left(q_{i}\right)=\delta \bar{f} q_{i} ; \quad q_{i} \in[0,1]
$$

for each $i \in I$. That is, each liquidity supplier offers the issuer to buy an arbitrary volume of her securities at the competitive price $\delta \bar{f}$. To check that these strategies form an equilibrium, suppose that all liquidity suppliers $i \in\{2, \ldots, I\}$ offer this schedule, while the first liquidity supplier offers an alternative schedule $\tilde{T}_{1}$. Now consider an issuer with type $f \in \mathcal{F}$. Then, whatever the volume $q_{1}$ of her securities that she sells to the first liquidity supplier, she will sell the remaining fraction $1-q_{1}$ to the other liquidity suppliers, since the price $\delta \bar{f}$ at which she can sell to them is higher than her retention cost $\delta f$. Hence, her problem can be written as:

$$
U_{F}(f)=\sup _{q_{1} \in[0,1]} \tilde{T}_{1}\left(q_{1}\right)+\delta \bar{f}\left(1-q_{1}\right)-\delta f .
$$

\footnotetext{
${ }^{8}$ For simplicity, we neglect the case where a constant transfer $\tau_{0}^{c}$ is needed to implement the competitive allocation.
} 
The remarkable fact about (14) is that the set of its solutions does not depend on $f$. This follows from the fact that all types of the issuer stands ready to sell their securities at the competitive price. Therefore we can assume that, out of the equilibrium path, the deviating liquidity supplier will face the same issuer distribution than the nondeviating ones, and that all types of the issuer sell the same volume of securities $q_{1}$ to him. If this is so, then the only way that the deviating liquidity supplier can attract the issuer is by offering a transfer $\tilde{T}_{1}\left(q_{1}\right) \geq \delta \bar{f} q_{1}$, thereby obtaining a profit:

$$
\left(\int_{\mathcal{F}} f d G^{\varphi}(f)-\frac{\tilde{T}_{1}\left(q_{1}\right)}{q_{1}}\right) q_{1},
$$

which is less or equal than what he would get by offering the competitive schedule, i.e., zero. It follows that the candidate strategies form an equilibrium. In this equilibrium, the issuer is able to sell all of her securities to the liquidity suppliers. Hence, we have proved the following decentralization result.

Proposition 9 If the issuer designs a security that involves no shut-down in the competitive case, there exists a perfect Bayesian equilibrium of the non-exclusive trading game that implements the competitive allocation.

The basic logic of this result is that of Bertrand competition: competition among liquidity suppliers allows to implement a constrained efficient allocation. We stress that the non-exclusivity clause plays a crucial role in the above argument, in that it ensures that no cream-skimming deviation is possible from the competitive schedule: any deviation that would attract some type of the issuer would also attract the other types. As a result, the transfer schedule (13) is entry-proof in the sense of Rothschild and Stiglitz (1976): no liquidity supplier can deviate by offering an alternative schedule without losing money. It should be noted that, in contrast with other models of competition in trading mechanisms such as Biais, Martimort and Rochet (2000), this result does not require a large number of liquidity suppliers. This intuitively follows from the fact that, because of the linearity of preferences, the optimal mechanism can be implemented through a fixed price schedule.

Exclusive Dealing. It is interesting to contrast the above decentralization result with what happens if the issuer can deal with only one liquidity supplier at a time, so that competition occurs only at the mechanism offering stage. Let us suppose that the issuer designs the optimal competitive debt contract with face value $d^{c}$, and, by way of contradiction, that there is an equilibrium of the trading game that implements the competitive allocation. Then in this candidate equilibrium, the issuer should sell $100 \%$ of her securities to one of the liquidity suppliers for a price $\delta d^{c}$, and each liquidity supplier must receive zero profit. Now suppose that one of the liquidity suppliers deviates by offering to buy a volume $q<1$ of the securities against a transfer $T_{\varepsilon}=$ 
$\delta d^{c} q+\varepsilon$, for some small $\varepsilon>0$. This offer will only attract the types:

$$
f>d^{c}-\frac{\varepsilon}{\delta(1-q)}
$$

of the issuer, thus securing a profit:

$$
\int_{d^{c}-\frac{\varepsilon}{\delta(1-q)}}^{d^{c}}\left(\left(f-\delta d^{c}\right) q-\varepsilon\right) g(f) d f+\left((1-\delta) d^{c} q-\varepsilon\right)\left(1-G\left(d^{c}\right)\right),
$$

which is strictly positive for $\varepsilon$ small enough. Thus, we have the following result.

Proposition 10 If the issuer designs a debt contract with face value $d^{c}$, there exists no perfect Bayesian equilibrium of the exclusive trading game that implements the competitive allocation.

Thus perfect pooling does not survive the possibility of offering exclusive contracts. As the above argument makes clear, the difference with the non-exclusive case is that, when other liquidity suppliers behave competitively, it is always possible to offer a cream-skimming deviation that will attract only the good types of the issuer. This type of deviation offers those types the opportunity to signal their high cash-flows by voluntarily restricting their volume of trade and thus bearing some positive retention cost, as in Leland and Pyle (1977) or DeMarzo and Duffie (1999).

\section{Conclusion}

This paper analyzes the links between the characteristics of securities and their liquidity. Our theoretical analysis extends the insightful recent paper by DeMarzo and Duffie (1999). A distinctive feature of our analysis is that we take a mechanism design approach to characterize both the optimal security and the optimal trading mechanism. This allows us to compare competitive and monopolistic liquidity supply in a unified framework.

In line with Myers and Majluf (1984), we find that the optimal security is debt. In the case where liquidity suppliers are competitive, the intuition is that debt is the less information sensitive security, and thus minimizes the consequences of adverse selection. Moreover, in the monopolistic case, debt optimally mitigates with the adverse consequences of market power on the gains from trade. In contrast with the signaling equilibrium analyzed by DeMarzo and Duffie (1999), the optimal debt contract is perfectly liquid: all issuer types sell $100 \%$ of their holdings of this security. Consequently, debt issuance does not convey a negative signal to the market, and, correspondingly, has no price impact. This is in line with the results of several empirical studies (see, e.g., Dann and Mikkelson (1984), Eckbo (1986), and Mikkelson and Partch (1986)). 
Our main results are robust to relaxing two assumptions of our basic model, which were also made in the earlier literature on security design under adverse selection (Nachman and Noe (1994) or DeMarzo and Duffie (1999)). In the competitive case, the optimal security and trades are unchanged if one allows the issuer to design a menu of securities, instead of a single security. Furthermore, no monotonicity assumptions need to be imposed. This points at the qualitative difference between our analysis of the optimality of debt, which does not rely upon monotonicity restrictions, and the moral hazard setting of Innes (1990) whereby, without these restrictions, the optimal contract allocates all the cash-flows to the outside financier up to a given threshold, and all the cash-flows to the inside manager above that threshold.

Finally, the constrained efficient allocation reached in the competitive liquidity supply case, where the issuer designs the trading mechanism, can be decentralized by allowing multiple liquidity suppliers to offer non-exclusive transfer schedules, as in financial markets where liquidity suppliers compete in limit orders to buy, or bid prices. 


\section{APPENDIX}

Proof of Lemma 1. Part (i) follows from the fact that $U_{F}$ is the maximum of a family of affine functions, as is easily seen from (2). As a convex function, $U_{F}$ is a.e. differentiable (see, e.g., Rockafellar (1970, Theorem 25.5)). Part (ii) then immediately follows from the envelope theorem.

Proof of Proposition 1. Fix a security $F$. Using the incentive constraint for types $f, \tilde{f} \in \mathcal{F}$ of the issuer, it is easy to check that:

$$
-\delta(\tilde{f}-f) q(f) \leq U_{F}(\tilde{f})-U_{F}(f) \leq-\delta(\tilde{f}-f) q(\tilde{f}) ; \quad(f, \tilde{f}) \in \mathcal{F}^{2} .
$$

Since $q$ is bounded, this implies that $U_{F}$ is Lipschitzian, hence absolutely continuous on $\mathcal{F}$. As $\dot{U}=-\delta q$ a.e. on $\mathcal{F}$, this implies that for all $f \in \mathcal{F}, U_{F}(f)=\delta \int_{f}^{\bar{f}} q(\phi) d \phi+U_{F}(\bar{f})$. In the competitive case, we may substitute this in the binding participation constraint of the liquidity supplier:

$$
U_{F}(\bar{f})=\int_{\mathcal{F}}\left((1-\delta) f q(f)-\delta \int_{f}^{\bar{f}} q(\phi) d \phi\right) d G^{\varphi}(f) .
$$

Using the fact that $G^{\varphi}$ is a right-continuous function of bounded variation, we may integrate by parts (see, e.g., Dellacherie and Meyer (1982, Theorem VI.90)) to obtain:

$$
\int_{\mathcal{F}} \int_{f}^{\bar{f}} q(\phi) d \phi d G^{\varphi}(f)=\int_{\mathcal{F}} G^{\varphi}\left(f^{-}\right) q(f) d f,
$$

where $f \mapsto G^{\varphi}\left(f^{-}\right)$is the left-continuous regularization of $G^{\varphi}$, which satisfies $G^{\varphi}\left(\underline{x}^{-}\right)=0$ by convention. Hence the issuer's problem is to maximize:

$$
(1-\delta) \int_{\mathcal{F}} f q(f) d G^{\varphi}(f)
$$

with respect to $q$ non-increasing and taking its values in $[0,1]$, and subject to:

$$
(1-\delta) \int_{\mathcal{F}} f q(f) d G^{\varphi}(f)-\delta \int_{\mathcal{F}} G^{\varphi}\left(f^{-}\right) q(f) d f \geq 0 .
$$

The Lagrangian for this problem is:

$$
(1+\lambda)(1-\delta) \int_{\mathcal{F}} f q(f) d G^{\varphi}(f)-\lambda \delta \int_{\mathcal{F}} G^{\varphi}\left(f^{-}\right) q(f) d f=\int_{\mathcal{F}} q(f) d H_{\lambda}(f),
$$

where, for any $\lambda \geq 0, H_{\lambda}: f \mapsto(1+\lambda)(1-\delta) \int_{f}^{f} \phi d G^{\varphi}(\phi)-\lambda \delta \int_{f}^{f} G^{\varphi}\left(\phi^{-}\right) d \phi$ is a right-continuous function of bounded variation. It is immediate to see that an optimal $q$ must be left-continuous. Hence, we may integrate by parts to obtain:

$$
\int_{\mathcal{F}} q(f) d H_{\lambda}(f)=\int_{\mathcal{F}}\left(H_{\lambda}(f)-H_{\lambda}(\bar{f})\right) d(1-q)\left(f^{+}\right),
$$

where $f \mapsto q\left(f^{+}\right)$is the right-continuous regularization of $q$. For any fixed $\lambda \geq 0$, the maximum of the Lagrangian is obtained by putting all the weight of the measure with distribution $f \mapsto 1-q\left(f^{+}\right)$ 
on the maxima of the function $H_{\lambda}$. Such a maximum exists because $H_{\lambda}$ is by construction upper semicontinuous. To determine the optimal schedule, let us introduce:

$$
f_{F}^{c}=\max \left\{f \in \mathcal{F} \mid(1-\delta) \int_{\underline{f}}^{f} \phi d G^{\varphi}(\phi)-\delta \int_{\underline{f}}^{f} G^{\varphi}\left(\phi^{-}\right) d \phi \geq 0\right\} .
$$

That the max is attained follows from the fact that $f \mapsto(1-\delta) \int_{\underline{f}}^{f} \phi d G^{\varphi}(\phi)-\delta \int_{\underline{f}}^{f} G^{\varphi}\left(\phi^{-}\right) d \phi$ is upper semicontinuous. It is immediate to verify that $f_{F}^{c}$ is the solution to the problem of maximizing:

$$
(1-\delta) \int_{\underline{f}}^{f} \phi d G^{\varphi}(\phi)
$$

subject to:

$$
(1-\delta) \int_{\underline{f}}^{f} \phi d G^{\varphi}(\phi)-\delta \int_{\underline{f}}^{f} G^{\varphi}\left(\phi^{-}\right) d \phi \geq 0 .
$$

The Lagrangian for this problem is precisely $H_{\lambda}$. Hence there exists $\lambda$ such that $f_{F}^{c}$ is the maximum of $H_{\lambda}$. Since $\chi_{\left[f, f_{F}^{c}\right]}$ satisfies the constraint of the original problem, this implies that the optimal quantity schedule $q^{c}$ has the required bang-bang property, and the optimal shut-down level is $f_{F}^{c}$. In the monopolistic case, we have $U_{F}(\bar{f})=0$, and the liquidity supplier's objective becomes:

$$
\int_{\mathcal{F}}\left((1-\delta) f q(f)-\delta \int_{f}^{\bar{f}} q(\phi) d \phi\right) d G^{\varphi}(f) .
$$

Along the same lines as above, we find that the liquidity supplier's problem is to maximize:

$$
\int_{\mathcal{F}}(1-\delta) f q(f) d G^{\varphi}(f)-\delta \int_{\mathcal{F}} G^{\varphi}\left(f^{-}\right) q(f) d f
$$

with respect to $q$ non-increasing and taking its values in $[0,1]$. The result follows immediately from the linearity of this objective with respect to $q$ and the constraint that $q$ be non-increasing. That $f_{F}^{c} \geq f_{F}^{m}$ follows from a direct comparison of the isssuer's and the liquidity supplier's objectives. Finally, suppose that $\tau_{0}^{c}>0$ while $f_{F}^{c}<\bar{f}$. Then the liquidity supplier's break-even constraint yields:

$$
\tau_{0}^{c}=\int_{\underline{f}}^{f_{F}^{c}}\left(f-\delta f_{F}^{c}\right) d G^{\varphi}(f),
$$

while the issuer's expected rent is given by:

$$
(1-\delta) \int_{\underline{f}}^{f_{F}^{c}} f d G^{\varphi}(f)
$$

It is then clear that the issuer could strictly gain by decreasing slightly the lump-sum tax $\tau_{0}^{c}$ and increasing the threshold $f_{F}^{c}$ while still preserving the break-even constraint, a contradiction.

Proof of Proposition 2. Consider first the competitive case. We can assume w.l.o.g. that $f_{F}^{c}<\bar{x}$. In that case, we have $\tau_{0}^{c}=0$ and the price at which equity is traded is $\delta f_{F}^{c}$. The result then follows 
from saturating the liquidity supplier's break-even constraint. Consider next the monopolistic case. Ignoring first the convexity constraint on $U_{E}$, and proceeding as in the proof of Proposition 1 , the liquidity supplier's objective can be expressed, after an integration by parts, as:

$$
\int_{\mathcal{F}}\left((1-\delta) f q(f)-\delta \int_{f}^{\bar{x}} q(\phi) d \phi\right) g(f) d f=\int_{\mathcal{F}}\left((1-\delta) f-\delta \frac{G(f)}{g(f)}\right) q(f) g(f) d f .
$$

Pointwise maximization with respect to $q$ implies that $q=1$ on the set of $f \in \mathcal{X}$ such that $\frac{1-\delta}{\delta} f \geq \frac{G(f)}{g(f)}$ and $q=0$ elsewhere. Condition (8) ensures that this set is an interval. Hence the associated rent $U_{E}(f)=\delta\left(f_{E}^{m}-f\right) \chi_{\left\{f \leq f_{E}^{m}\right\}}$ is convex in $f$, which implies the result.

Proof of Proposition 3. Consider first the competitive case. Suppose w.l.o.g. that $f_{E}^{c}<\bar{x}$, so that an equity contract would imply some shut-down on the part of issuer. If $d<f_{E}^{c}$, then the issuer does not want to shut-down any type $f \in[\underline{x}, d]$, for otherwise she would like to lower the shut-down threshold from $f_{E}^{c}$ when she offers equity. Suppose now that $d=f_{E}^{c}$. By the above reasoning, if the issuer shut-downs some types below $f_{E}^{c}$, she obtains at most:

$$
(1-\delta) \int_{\underline{f}}^{f_{E}^{c}} f g(f) d f
$$

This is clearly less than what she obtains if she does not shut-down any type and saturate the liquidity supplier's break-even constraint, i.e.,

$$
(1-\delta)\left(\int_{\underline{f}}^{f_{E}^{c}} f g(f) d f+\left(1-G\left(f_{E}^{c}\right)\right) f_{E}^{c}\right)
$$

By continuity, it is clear that for any $d \in\left[f_{E}^{c}, d^{c}\right]$, the issuer will not shut-down any type when the traded contract is a standard debt contract with face value $d$, while still preserving the liquidity supplier's break-even constraint. Consider next the monopolistic case. Suppose w.l.o.g. that $f_{E}^{m}<\bar{x}$, so that an equity contract would imply some shut-down on the part of the liquidity supplier. If $d<f_{E}^{m}$, then the liquidity supplier does not want to shut-down any type $f \in[\underline{x}, d]$, for otherwise he would like to lower the shut-down threshold from $f_{E}^{m}$ when the issuer offers an equity contract. Suppose now that $d=f_{E}^{m}$. By the above reasoning, if the liquidity supplier shut-downs some types below $f_{E}^{m}$, he obtains at most:

$$
\int_{\underline{x}}^{f_{E}^{m}} f g(f) d f-\delta f_{E}^{m} G\left(f_{E}^{m}\right)
$$

since (8) holds. If $f_{E}^{m}<\bar{x}$ so that $G\left(f_{E}^{m}\right)<1$, then, since $\delta<1$, this is clearly less than what he obtains if he does not shut-down any type, i.e.,

$$
\int_{\underline{x}}^{f_{E}^{m}} f g(f) d f+f_{E}^{m}\left(1-G\left(f_{E}^{m}\right)\right)-\delta f_{E}^{m} .
$$

By continuity, it is clear that for any $d \in\left[f_{E}^{m}, d^{m}\right]$, the liquidity supplier will not shut-down any type of the issuer when the traded contract is a standard debt contract with face value $d$. 
Proof of Lemma 3. In the competitive case, this follows at once from the fact that the issuer maximizes the gains from trade. In the monopolistic case, let us suppose that $F$ is an optimal design such that $\varphi(\underline{x})<\underline{x}$. Then, given (MR), there exists $\varepsilon>0$ such that $\varphi(x)<x-\varepsilon$ for all $x \in \mathcal{X}$. Consider the design $F_{\varepsilon}$ defined by $\varphi_{\varepsilon}=\varphi+\varepsilon$. By Proposition 1, given this new design, the liquidity supplier chooses a shut-down threshold $\tilde{f}$ so as to maximize his expected profit:

$$
\int_{\underline{f}+\varepsilon}^{\tilde{f}}(f-\delta \tilde{f}) d G^{\varphi} \varepsilon(f)=\int_{\underline{f}}^{\tilde{f}-\varepsilon}(f-\delta(\tilde{f}-\varepsilon)) d G^{\varphi}(f)+(1-\delta) \varepsilon G^{\varphi}(\tilde{f}-\varepsilon) .
$$

The first term on the right-hand side of this equation is maximized by setting $\tilde{f}=f_{F}^{m}+\varepsilon$, where $f_{F}^{m}$ is the liquidity supplier's optimal shut-down threshold for security $F$. Since the second term is nondecreasing in $\tilde{f}$, this implies that the optimal shut-down threshold $f_{F_{\varepsilon}}^{m}$ for the new design is greater or equal than $f_{F}^{m}+\varepsilon$. It is then easy to check that the issuer's expected rent under the design $F_{\varepsilon}$ is at least as large as under $F$.

Proof of Proposition 5. Consider first the competitive case. Suppose that $F$ is a security sold at a price $\delta f_{F}^{c}$ for which $f_{E}^{c}<\bar{f}$. To show that this cannot be optimal, we show that there exists an alternative security and transfer which Pareto dominates $F$. Consider the design $\bar{F}$ defined by $\bar{\varphi}=\min \left\{\varphi, f_{F}^{c}\right\}$ with price $\delta f_{F}^{c}+\varepsilon$ for some $\varepsilon>0$. By construction, issuers with $\bar{\varphi}(x)<f_{F}^{c}$ are still willing to trade. Issuers with $\bar{\varphi}(x)=f_{F}^{c}$ are ready to trade since by doing so their informational rent is $\varepsilon$ instead of zero. Consider now the liquidity suppliers. Their expected profit under $F$ is:

$$
\int_{\underline{f}}^{f_{F}^{c}}\left(f-\delta f_{F}^{c}\right) d G^{\varphi}(f)
$$

while their expected profit under $\bar{F}$ is:

$$
\int_{\underline{f}}^{f_{F}^{c}}\left(f-\delta f_{F}^{c}\right) d G^{\varphi}(f)+(1-\delta)\left(1-G^{\varphi}\left(f_{F}^{c}\right)\right)-\varepsilon .
$$

Since $G^{\varphi}\left(f_{F}^{c}\right)<1$, they are strictly better off under the new design for $\varepsilon$ small enough. Consider next the monopolistic case. Suppose by way of contradiction that $F$ is an optimal security such that the liquidity supplier shut-downs the types above $f_{F}^{m}<\bar{f}$, thereby obtaining a profit:

$$
\int_{\underline{f}}^{f_{F}^{m}}\left(f-\delta f_{F}^{m}\right) d G^{\varphi}(f)
$$

Consider the design $F_{\varepsilon}$ defined by $\varphi_{\varepsilon}=\min \left\{\varphi, f_{F}+\varepsilon\right\}$ for $\varepsilon>0$. Since $f_{F}^{m}<\bar{f}, \varphi$ is continuous, and the density $g$ is positive on $\mathcal{X}$, one can choose $\varepsilon$ such that $G^{\varphi}\left(f_{F}^{m}+\varepsilon^{-}\right)<1$. If the liquidity supplier decides to shut-down some types below $f_{F}^{m}+\varepsilon$ given this new design, the optimal way to do so is to set $f_{F_{\varepsilon}}^{m}=f_{F}^{m}$, for a profit equal to that which obtains under $F$. However, if he decides not to shut-down any type, the liquidity supplier obtains:

$$
\int_{\underline{f}}^{f_{F}^{m}+\varepsilon}\left(f-\delta\left(f_{F}^{m}+\varepsilon\right)\right) d G^{\varphi_{\varepsilon}}(f)
$$


which can be rewritten as:

$$
\int_{\underline{f}}^{f_{F}^{m}}\left(f-\delta\left(f_{F}^{m}+\varepsilon\right)\right) d G^{\varphi}(f)+\int_{f_{F}^{m}}^{f_{F}^{m}+\varepsilon^{-}}\left(f-\delta\left(f_{F}^{m}+\varepsilon\right)\right) d G^{\varphi}(f)+(1-\delta)\left(f_{F}^{m}+\varepsilon\right)\left(1-G^{\varphi}\left(f_{F}^{m}+\varepsilon^{-}\right)\right) \text {. }
$$

The first term converges to $\int_{\underline{f}}^{f_{F}^{m}}\left(f-\delta f_{F}^{m}\right) d G^{\varphi}(f)$ as $\varepsilon$ goes to 0 . Moreover, for $\varepsilon$ small enough, the second term in this expression is positive. Since the last term is positive and bounded away from zero for $\varepsilon$ small enough, the liquidity supplier obtains strictly more by not shutting down any type. It is then immediate to check that the issuer's expected rent under the design $F_{\varepsilon}$,

$$
\delta \int_{\underline{f}}^{f_{F}^{m}+\varepsilon}\left(f_{F}^{m}+\varepsilon-f\right) d G^{\varphi_{\varepsilon}}(f)=\delta \int_{\underline{f}}^{f_{F}^{m}+\varepsilon^{-}}\left(f_{F}^{m}+\varepsilon-f\right) d G^{\varphi}(f),
$$

is strictly larger than under $F$. Hence $F$ cannot be an optimal security, which implies the result.

Proof of Proposition 6. For any fixed $\lambda>0$, we study the problem of maximizing $L(\varphi, \lambda)$ with respect to $\varphi \in \Phi$. We treat this as an optimal control problem with state variable $\varphi$ and control variable $\dot{\varphi}$, with the additional restriction that $0 \leq \dot{\varphi} \leq 1$. The Hamiltonian can be written as:

$$
H(x, \varphi(x), p(x), v)=-(1+\lambda-\delta) v G(x)+p(x) v
$$

where $v$ is the control variable and $p$ the co-state variable. By Pontryagin's maximum principle, a necessary condition for $(\varphi, v)$ to be optimal is that $v$ maximizes pointwise the Hamiltonian for some $p$ that satisfies the Hamilton-Jacobi equation:

$$
\dot{p}(x)=-\frac{\partial H}{\partial \varphi}(x, \varphi(x), p(x), v(x))=0
$$

at all points of continuity of $v$. Since the boundary $\bar{x}$ is free, the transversality condition yields $p(\bar{x})=(1-\delta)(1+\lambda)$ so that $p$ is constant and equal to $(1-\delta)(1+\lambda)$. Substituting this back into the Hamiltonian, we find that an optimal control is:

$$
v(x)=\chi_{\{-(1+\lambda-\delta) G(x)+(1-\delta)(1+\lambda) \geq 0\}} .
$$

Since the Hamiltonian is linear in $(\varphi, v)$, Mangasarian's sufficiency conditions are satisfied, so $v$ is indeed optimal. Note that since the mapping $x \mapsto-(1+\lambda-\delta) G(x)+(1-\delta)(1+\lambda)$ is decreasing, the corresponding $\varphi$ is a debt contract with face value $d$ satisfying $-(1+\lambda-\delta) G(d)+(1-\delta)(1+\lambda)=0$. Thus provided that $G\left(d^{c}\right)>1-\delta, \varphi=\min \left\{\operatorname{Id}_{\mathcal{X}}, d^{c}\right\}$ maximizes $L(\varphi, \lambda)$ whenever:

$$
\lambda=\frac{(1-\delta)\left(1-G\left(d^{c}\right)\right)}{G\left(d^{c}\right)-(1-\delta)} .
$$

It is easy to check that the optimal debt contract from the liquidity supplier's point of view satisfies $G(d)=1-\delta$. Hence $G\left(d^{c}\right)>1-\delta$ as required. Since for this contract we have $\int_{\mathcal{X}} \varphi(x) g(x) d x=\delta \varphi(\bar{x})$, the conclusion follows directly from Luenberger $(1969, \S 8.3$, Theorem 1$)$.

Proof of Lemma 4. Suppose by way of contradiction that $\tilde{\varphi}$ guarantees the issuer a higher payoff than $\varphi$, i.e.,

$$
\delta \int_{\mathcal{X}}(\tilde{\varphi}(\bar{x})-\tilde{\varphi}(x)) g(x) d x>\delta \int_{\mathcal{X}}(\varphi(\bar{x})-\varphi(x)) g(x) d x
$$


while satisfying the no shut-down condition:

$$
\int_{\mathcal{X}}(\tilde{\varphi}(x)-\delta \tilde{\varphi}(\bar{x})) g(x) d x \geq \int_{\underline{x}}^{\tilde{x}}(\tilde{\varphi}(x)-\delta \tilde{\varphi}(\tilde{x})) g(x) d x ; \quad \tilde{x} \in \mathcal{X} .
$$

The no shut-down condition on $\tilde{\varphi}$, together with the fact that $\Lambda$ defines a positive measure on $\mathcal{X}$, implies:

$$
\int_{\mathcal{X}}\left(\int_{\mathcal{X}}(\tilde{\varphi}(x)-\delta \tilde{\varphi}(\bar{x})) g(x) d x-\int_{\underline{x}}^{\tilde{x}}(\tilde{\varphi}(x)-\delta \tilde{\varphi}(\tilde{x})) g(x) d x\right) d \Lambda(\tilde{x}) \geq 0 .
$$

But then, since:

$$
\int_{\mathcal{X}}\left(\int_{\mathcal{X}}(\varphi(x)-\delta \varphi(\bar{x})) g(x) d x-\int_{\underline{x}}^{\tilde{x}}(\varphi(x)-\delta \varphi(\tilde{x})) g(x) d x\right) d \Lambda(\tilde{x})=0,
$$

we would get that $L(\tilde{\varphi}, \Lambda)>L(\varphi, \Lambda)$, a contradiction.

Proof of Lemma 5. For any fixed $\lambda>1$, we study the problem of maximizing $L\left(\varphi, \Lambda_{\lambda}\right)$ with respect to $\varphi \in \Phi$. Re-arranging the expression of $L\left(\varphi, \Lambda_{\lambda}\right)$, we obtain:

$$
L\left(\varphi, \Lambda_{\lambda}\right)=\delta \int_{\underline{x}}^{f_{E}^{m}} \dot{\varphi}(x) G(x) d x+\int_{f_{E}^{m}}^{\bar{x}}((1-\lambda) \delta \dot{\varphi}(x) G(x)+\lambda(1-\delta) \varphi(x) g(x)) d x .
$$

Since $\lambda>0$, it is clear that it is optimal to set $\varphi(x)=x$ on $\left[\underline{x}, f_{E}^{m}\right]$. We are thus left with the problem of maximizing:

$$
\int_{f_{E}^{m}}^{\bar{x}}((1-\lambda) \delta \dot{\varphi}(x) G(x)+\lambda(1-\delta) \varphi(x) g(x)) d x
$$

with respect to functions $\varphi$ on $\left[f_{E}^{m}, \bar{x}\right]$ satisfying $(\mathrm{LL})-(\mathrm{M})-(\mathrm{MR})$. We treat this as an optimal control problem with state variable $\varphi$ and control variable $\dot{\varphi}$, with the additional restriction that $0 \leq \dot{\varphi} \leq 1$. The Hamiltonian can be written as:

$$
H(x, \varphi(x), p(x), v)=(1-\lambda) \delta v G(x)+\lambda(1-\delta) \varphi(x) g(x)+p(x) v
$$

where $v$ is the control variable and $p$ the co-state variable. By Pontryagin's maximum principle, a necessary condition for $(\varphi, v)$ to be optimal is that $v$ maximizes pointwise the Hamiltonian for some $p$ that satisfy the Hamilton-Jacobi equation:

$$
\dot{p}(x)=-\frac{\partial H}{\partial \varphi}(x, \varphi(x), p(x), v(x))=-\lambda(1-\delta) g(x)
$$

at all points of continuity of $v$. Since the boundary $\bar{x}$ is free, the transversality condition yields $p(\bar{x})=0$, so that $p=\lambda(1-\delta)(1-G)$. Substituting this back into the Hamiltonian, we find that a candidate optimal control is:

$$
v(x)=\chi_{\{(\delta-\lambda) G(x)+\lambda(1-\delta) \geq 0\}} .
$$

Since the Hamiltonian is linear in $(\varphi, v)$, Mangasarian's sufficiency conditions are satisfied, so $v$ is indeed optimal. Note that since the mapping $x \mapsto(\delta-\lambda) G(x)+\lambda(1-\delta)$ is decreasing as $\lambda>1>\delta$, 
the corresponding $\varphi$ is to a debt contract with face value $d$ satisfying $(\delta-\lambda) G(d)+\lambda(1-\delta)=0$. Thus, provided that $G\left(d^{m}\right)>1-\delta, \varphi=\min \left\{\operatorname{Id}_{\mathcal{X}}, d^{m}\right\}$ maximizes $L\left(\varphi, \Lambda_{\lambda}\right)$ whenever:

$$
\lambda=\frac{\delta G\left(d^{m}\right)}{G\left(d^{m}\right)-(1-\delta)} .
$$

It is easy to check that the optimal debt contract from the liquidity supplier's point of view satisfies $G(d)=1-\delta$. Hence $G\left(d^{m}\right)>1-\delta$, which concludes the proof as $\lambda>1$ whenever $d^{m}<\bar{x}$. 


\section{REFERENCES}

Akerlof, G. (1970): "The Market for Lemons, Qualitative Uncertainty and the Market Mechanism," Quarterly Journal of Economics, 84, 488-500.

Allen, F., and D. Gale (1988): "Optimal Security Design," Review of Financial Studies, 1, 229-263.

Baron, D., and R. Myerson (1982): "Regulating a Monopolist with Unknown Costs," Econometrica, 50, 911-930.

Benveniste, L., W.Y. Busaba, and W.J. Wilhelm, Jr (2002): "Information Externalities and the Role of Underwriters in Primary Equity Markets," Journal of Financial Intermediation, 11, 61-86.

Benveniste, L., W.J. Wilhelm, Jr, and X. Yu (1999): "Evidence on Information Spillovers in the Production of Investment Banking Services," working paper, University of Minnesota.

Biais, B., and A.-M. Faugeron-Crouzet (2002): "IPO Auctions: English, Dutch, ... French, and Internet," Journal of Financial Intermediation, 11, 9-36.

D. Martimort, and J.-C. Rochet (2000): "Competing Mechanisms in a Common Value Environment," Econometrica, 68, 799-837.

Brealey, R., and S. Myers (2000): Principles of Corporate Finance, New York, Irwin McGraw-Hill.

Chen, H., and J. Ritter (2000): "The Seven Per Cent Solution," Journal of Finance, 55, 1105-1131.

Christie, W., and P. Schultz (1994): "Why Do Nasdaq Market Makers Avoid Odd Eighth Quotes?," Journal of Finance, 49, 1813-1840.

Cornelli, F., and D. Goldreich (1998): "Book Building and Strategic Allocation," working paper, London Business School.

Dann, L., and W. Mikkelson (1984): "Convertible Debt Issuance, Capital Structure Change and Financing Related Information: Some New Evidence," Journal of Financial Economics, 13, 157-186.

Dellacherie, C., and P.-A. Meyer (1982): Probabilities and Potential, Volume B, Amsterdam, North-Holland.

DeMarzo, P., and D. Duffie (1999): "A Liquidity-Based Model of Security Design," Econometrica, 67, 65-99. 
EckBo, E. (1986): "Valuation Effects of Corporate Debt Offerings," Journal of Financial Economics, 15, 119-151.

FreiXas, X., and J.C. Rochet (1997): Microeconomics of Banking, MIT Press, Boston.

Gale, D., and M. Hellwig (1985): "Incentive Compatible Debt Contracts: The One Period Problem," Review of Economic Studies, 52, 647-663.

Glosten, L. (1989): "Insider Trading, Liquidity and the Role of the Monopolist Specialist," Journal of Business, 62, 211-236.

(1994): "Is the Electronic Open Limit Order Book Inevitable?" Journal of Finance, 49, 1127-1161.

Grindblatt, M., and S. Titman (1998): Financial Policy and Corporate Strategy, New York, Irwin McGraw-Hill.

Hanley, K.W., and W.J. Wilhelm, Jr (1995): "Evidence on the Strategic Allocation of IPOs," Journal of Financial Economics, 37, 239-257.

Harris, M., and A. RAviv (1989): "The Design of Securities," Journal of Financial Economics, 24, 255-287.

Holmström, B., and R. Myerson (1983): "Efficient and Durable Decision Rules with Asymmetric Information," Econometrica, 51, 1799-1899.

InNES, R. (1990): "Limited Liability and Incentive Contracting with Ex-Ante Action Choices," Journal of Economic Theory, 52, 45-67.

Kyle, A.S. (1985): "Continuous Auctions and Insider Trading," Econometrica, 53, 1335-1355.

Leland, H., and D. Pyle (1977): "Information Asymmetries, Financial Structure and Financial Intermediaries," Journal of Finance, 32, 371-387.

Luenberger, D.G. (1969): Optimization by Vector Space Methods, New York, John Wiley and Sons.

Martimort, D. (1992): "Multi-Principaux avec Anti-Sélection," Annales d'Economie et de Statistiques, 28, 1-38.

Mikkelson, W., and M. PARTCH (1986): "Valuation effects of security offerings and the issuance process," Journal of Financial Economics, 15, 31-60. 
Myers, S., and N. Majluf (1984): "Corporate Financing and Investment Decisions when Firms Have Information Investors Do not Have," Journal of Financial Economics, 13, 187-221.

Myerson, R. (1979): "Incentive Compatibility and the Bargaining Problem," Econometrica, 47, 61-73.

Nachman, D.C., and T.H. Noe (1994): "Optimal Design of Securities under Asymmetric Information," Review of Financial Studies, 7, 1-44.

Riley, J., and R. Zeckhauser (1983): "Optimal Selling Strategies: When to Haggle, When to Hold Firm," Quarterly Journal of Economics, 118, 267-289.

Rockafellar, R.T. (1970): Convex Analysis, Princeton, Princeton University Press.

Rothschild, M., and J. Stiglitz (1976): "Equilibrium in Competitive Insurance Markets," Quarterly Journal of Economics, 90, 629-649.

Stole, L. (1990): "Mechanism Design under Common Agency," mimeo, University of Chicago.

Townsend, R. (1979): "Optimal Contracts and Competitive Markets with Costly State Verification," Journal of Economic Theory, 21, 265-293. 